\title{
Palavras do exílio
}

Este discurso foi lido pelo professor Dr. J. J. Cardozo de Mello Neto, representando o professor Dr. Waldemar Ferreira, em banquete que a êste, como seu paraninfo, ofereceram aos 26 de janeiro de 1933, no salão São Paulo, do Clube Comercial, os bacharelandos da turma de 1933.

Atendo, senhores bacharelandos, meus presados discipulos e jovens colegas, ao vosso chamamento. Desejastesme ao vosso lado, como paraninfo de vossa colação de gráu. Aqui me tendes, nesta tribuna, onde ainda vibram as palavras do vosso orador, impregnadas de uns toques de posteridade, afirmação vigorosa de juventude disposta a caminhar para a frente. O panorama é o mesmo de todos os dezembros. A liturgia acadêmica é pobre. Está em festas êste salão vetusto, de paredes forradas de figuras antigas de velhos professores, fisionomias imobilizadas na tela, no mármore e no bronze, ilusão com que se costuma supor eterna a transitória perpetuidade das coisas humanas, a co. brirem-se, imperceptivelmente, com a poeira do tempo.

Não sentis? Olhos brilhantes de mulheres formosas cinti- 
lam de esperanças no redemoinhar de promessas proferidas no silêncio dos colóquios mudos. Marejam-se de lágrimas puríssimas olhos de mãis, embevecidos na contemplação de um episódio feliz, de ha muito esperado. Satura o ambiente a ruidosa alegria das realizações iniciadas. Sons. Flores. Coloridos. Anseios. Lampejos de glórias. A sensação de mais um degrau subido e a vastidão de um horizonte mais largo.

Procuram-me, meus valorosos soldados da lei, os vossos olhares. Aguardam os vossos ouvidos a minha fala acentuadamente paulista. Ouvi-me. Se a palavra, neste instante pronunciada, não é minha pela sua sonoridade, pois outros lábios a emitem, minha, entretanto, ela é, inteiramente minha, pela sua essência e pela forma por que, por via dela, se exprime o meu pensamento e se representa a minha prsonalidade.

Dentro destas vestes talares, é certo, não estou eu. Como a imaginação é criadora e a memoria possúi mais duradoura retina, não é demasia exigir-lhe um pouco mais de esfôrço, afim de operar-se a transfiguração. A ausência, por milagre da saüdade, presença é, posto nos separe a imensidade de um oceano. Estamos, neste momento, em dois hemisférios: vós, meus compatrícios, nesta legendária terra de Piratininga, majestoso cenário das arrancadas de um povo forte, que, deixando o mar lá em baixo, ao pé da cordilheira do Paranapiacaba, avançou pelo sertão a dentro, dilatando as lindes territoriais do Brasil; e eu nesta gloriosa terra de Portugal, onde se formou a raça máscula da gente destemerosa, que, deixando o chão europeu atrás das suas remadas e dos sulcos das suas caravelas, navegou por mares nunca dantes navegados, dando ao mundo novos mundos. A epopéia das bandeiras foi o seguimento natural da das navegações. 0 mesmo ímpeto. A mesma audácia. A mesma perseverança. A mesma finalidade. Apenas, a diferença do tempo e do espaço.

Aquí estou, pois, sem estar. Bem sabeis a razão dêste afastamento material, que nos conserva, todavia, intelectual, 
moral, patriótica e afetivamente juntos, coparticipando das mesmas angústias e orgulhosos dos mesmos feitos.

Longe de vós, mas perto de vossos corações, que com tanta intensidade têm batido nestes últimos tempos, vejo o céu brasileiro a refletir as côres confusas do ambiente mundial, nas meias tintas de um ocaso interminável, a retardar os alvores matutinos.

E' de inquietude o minuto. Trepidam desejos insatisfeitos. Enervaram-se os espíritos pelo suceder de agitações imprevistas. Perturbaram-se os sentidos na multiplicidade das paixões desencadeadas. $\mathrm{E}$ a ânsia de viver, aguçada pela vertigem do século, veiu a ser mais alucinante. Greneralizou-se o desequilíbrio de um cosmos estratificado pela superposição das gerações. Tudo se foi mudando, na imaginação e, tambem, na realidade. 0 exagero das dissonâncias rompeu a unidade tonal, transmudando-se as regras da música pela implantação da polirritimia. Banida a riqueza da modulação e substituida pela mudança de tom, áspera e dura, encheu-se a harmonia de sincopes. Quebrou-se a dinâmica musical. $O$ ruido turbilhonante da vida moderna abafou as expressões suavíssimas da alma humana, que perdeu, assim, a sua poesia. Tambem esta, habituada a exteriorizar todos os sentimentos, desde a esperança ao desespero, provocando o êxtase e dando o consôlo, se desarticulou. As promessas de amor morreram, definitivamente, nas gargantas. Desmancharam-se as frases sonoras em palavras sôltas e sem ligação. $O$ verso, sem sentido e sem rima, deformou-se. A pintura, em vez de reproduzir a natureza através de temperamentos e êstes pelas suas expressões humanas, empastelou-se no baralhamento de tintas, manejados os pinceis por estudantes em começo de alfabetização ou por egressos casuais de manicômios. Adquiriu a plástica moldes primitivos, e o barro, tocado por mãos imperitas, perdeu as suas formas eternas, apresentando desageitadas figuras de alegorias abandonadas nas quartas feiras de cinzas. Elevou a arquitetura os edificios para o 
alto, com as suas colunas e paredes lisas, com estruturas de cimento armado, rapidamente construídos, mas externando, sem embargo da sua resistência, segurança e comodidade, a aparência das coisas efêmeras.

Exprimiu-se o belo por outras fórmulas, mais rudes, tidas como futuristas, mas, em verdade, ressurreições de antiguidades amortecidas nas dobras do passado. Futurismo. Passadismo. Não sòmente nas letras e nas artes, senão também nas mais notáveis criações de engenho humano.

Ainda não haviam cessado de troar os canhões francos e germânicos e uma das mais poderosas nações havia já sossobrado ao sôpro do vendavel comunista, que em terras da Rússia se implantara, rompendo com os velhos preconceitos sociais, políticos, econômicos e jurídicos do Estado e instituindo a ditadura do proletariado, sem pátria, sem família e sem religião. Prometeu ao homem a felicidade terrena, mas escravizou-o, arrebatando-lhe, até, a esperança consoladora, capaz de redimir os pecadores e a apaziguar os revoltados, de outra vida eterna e melhor. Materializou-lhe a contingência. Desfibrou-o. Desindividualizou-o. Converteu-o numa simples peça anônima do vasto e complicado maquinismo do Estado. Desapareceu o cidadão, com os seus direitos, célula do imenso tecido da unidade nacional. Ficou, em seu lugar, pura e simplesmente, o trabalhador, de enxada ou picareta ao ombro, tão dono do seu próprio eu e do seu destino como o boi ou o burro atrelado ao arado sulcador da terra, ou de qualquer outro animal prestante para os labôres do campo ou da cidade.

Passou o Estado a ser uma vasta associação cooperativa de produção e de consumo, adjudicadas a todos, igualmente, as utilidades do solo e da indústria. Comuns tornaram-se, também, as privações, as angústias, os sofrimentos impostos pelo meio exterior. E a miséria, moral e orgânica, tornou-se o denominador comum da vida. Nenhum privilégio ou vantagem. Nem ao músculo. Nem ao gênio. Nem à capacidade produtiva. Apoderou-se o Estado de tudo e tudo re- 
duziu a uma massa única, passando, como deus e senhor, a dar, a dirigir, a alimentar, a educar, a curar, enfim, a mover os homens, ao seu talante, por fios invisíveis, manejados pelas suas mãos tentaculares e poderosissimas.

Ficara, dessarte, no olvido tudo quanto a ciência e a experiência haviam acumulado, de princípios e de observações, no tocante à organização política das nações e ao govêrno dos povos. Estado de ditadura de uma classe, reconheceu o soviético a soberanía do proletariado. Longe de garantir os direitos individuais, reservou-se a faculdade discricionária de privar dêles não sòmente indivíduos isolados, senão grupos inteiros da população.

Não se propagou essa doutrina, entretanto: conteve-se dentro das fronteiras russas, posto a cessação da guerra houvesse trazido sérias dificuldades para todas as nações, facilitando a fomentação a fermentação das idéias subversivas. Sofreram as suas conseqüências reconstituindo-se geográfica e políticamente. As indústrias, levadas ao ponto de maior intensidade de trabalho e de produção, tendo ao seu dispôr exército de operários especializados, viram-se, de súbito, imobilizadas, ficando êles sem trabalho, ao desemprêgo. E os países se encontraram em face de problemas inéditos, jamais esboçados nos programas de seus governos.

Volveram-se, nesse transe, as queixas dos males, que a todos afligiam, contra o sistema liberal democrático dos Estados europeus. Decretára-se-lhes a falência, posto não haja ainda transitado em julgado a respetiva sentença. Pois não levara a democracia as nações às beiras dos abismos insondáveis da história?

Quem mais vigorosamente a atacou, depois de LenINe, foi Benito Mussolini. A concepção do Estado, na ideologia fascista, é absolutamente oposta à liberal democrática. O Estado fascista é fôrça e na fôrça repousa e entrosa-se: deve ser o Estado de tamanha autoridade, que seja esta soberana, dominadora de todas as fôrças no país existentes. Resultado da organização jurídica da sociedade, como êle o definiu, o Estado fascista tem vida própria e fins supe- 
riores, aos quais devem subordinar-se os fins particulares dos individuos. Também tem a sua moral, a sua religião, a sua missão política no mundo, a sua função de justiça social e o seu dever econômico. Nem os problemas da fé lhe escapam. E para a realização dessa finalidade requer e exige os meios adequados e o máximo de autoridade e de fôrça.

Falando, ainda há pouco, a um jornalista e escritor francês, Pierre Chanlaine, criticou Benito Mussolini a organização dos gabinetes governamentais democráticos. Salientou a heterogeneidade de suas forças. Defendeu a unidade da realização fascista, firmemente assegurada pelo seu chefe, como indispensável. "A fisionomia constitucional do primeiro ministro, que é o chefe do govêrno", disse, "assume particular relevância. Nada de compartimentos estanques, próprios do regime parlamentar, em que cada ministro, representando uma fôrça particular, um grupo particular e interêsses particulares, tende a fazer, no seio do govêrno, a sua própria política. Só eu tenho nas mãos a totalidade dos negócios, isto é, a direção geral do Estado. Eu dirijo, efetivamente, o govêrno. O concelho dos ministros, mesmo por ser um organismo consultivo da maior importância, não pode, pela sua natureza coletiva, ser o dinetor efetivo da vida política do país"

$\mathrm{E}$ viu o chefe do govêrno italiano uma das causas da decadência do Estado liberal democrático no acréscimo desmesurado dos poderes da câmara eletiva, em detrimento do poder executivo (1).

Ora, o Estado liberal democrático entrou em crise, em terras do Brasil, exatamente, pela absorção, pelo poder executivo, cada vez mais fortalecido e mais forte, das prerrogativas do poder legislativo. Teve êste, nos três últimos quadrienios constitucionais, notadamente, vida mesquinha e inglória. Por despojar-se de suas vestes, ficou maltrapilho.

(1) PIERRE CHANLAINE, Mussolini parla, ed. Tallandier (Paris), pág. 15. 
De tanto delegar ao executivo as suas funções converteu-se num órgão inútil, poder sem fôrça material, nem moral.

$\mathrm{E}$ o estado de coisas daí decorrente originou uma situação insuportável. O chefe do govêrno era, com efeito, soberano. Tinha, em suas mãos, a totalidade dos negócios, isto é, dirigia a política geral do Estado. E sem nenhum contraste. Todo o aparelhamento político e administrativo lhe estava, integralmente, sujeito. A sua vontade era a única vontade. A sua deliberação a cumprida, mesmo nos negócios particulares dos Estados federados. Era um govêrno forte, em toda a extensão da palavra. Apoiavam-no todos os govêrnos estaduais, à sua semelhança constituidos; e êles, mais os municipais, sustentados, em todo o país, por único partido: o do govêrno, orientado e dirigido pelo seu chefe, o presidente da República. Era o mesmo processo adotado pelo comunismo soviético, pelo fascismo italiano, pelo quemalismo turco e, agora, preconizado pelo integralismo lusitano. Tal soma de poderes enfeixara o chefe do govêrno brasileiro e tamanha pressão exercera sôbre o povo, comprimindo-o, que vários movimentos revolucionários contra êle explodiram e veiu, afinal, a vencer o de outubro de 1930.

Eis, pois, meus jovens colegas, uma desoladora verdade: o remédio, com que o fascismo terá salvo a Itália na hora suprema de sua história, foi o veneno que intoxicou o Brasil por muitos anos e cujos efeitos ainda não cessaram.

Pensa-se, não obstante, voltar a êle, não já com as vestes do presidencialismo americano, mas com a camisa preta fascista.

Não se esqueçam, todavia, os corifeos dessa jornada os reparos oportunos do grande chefe do govêrno italiano, prevenindo os que lhe quisessem seguir os passos. E' impossivel, discursou êle, no estrangeiro, copiar-se o fascismo, por serem diferentes as condições históricas, geográficas, econômicas e morais. O fenômeno é italiano e em regime para logo se transformou. Em nenhum outro país se reproduziu. Preferiram quasi todos manter o sistema democrático, introduzindo-lhe os corretivos indicados pelas suas necessidades. 
Comemorando o quarto aniversário da marcha sôbre Roma, vangloriou-se o famoso ditador italiano de ter "enterrado o velho Estado democrático, liberal, agnóstico e paralítico" com "funerais de terceira classe", substituindo-o pelo corporativo fascista. Entrevistado, recentemente, pelo jornalista francês referido, em outros termos se referiu, diante da evidência dos fatos. "Fora da Itália", asseverou, "e mais particularmente nos países anglo-saxões, tem o Estado liberal democrático conseguido desenvolver-se e, mesmo, realizar grandes coisas, por ter encontrado, na edução social e política dos povos os corretivos, que nos faltavam. Nesses países, e mesmo em França, existe uma grande concepção nacional e a concepção de cada Estado se fortificou através de séculos de lutas, sustentadas pela afirmação do poder. Demais, na Inglaterra, ao espirito individualista e desagregador do germanismo, veiu superpor-se uma moral rigorosa, graças à qual o indivíduo, mesmo reivindicando, teòricamente, a mais ampla liberdade em face do Estado, sabia, na prática, limitar as suas aspirações".

Não é, por via de conseqüência, como proclamam os arautos de novidades estranhas, ainda, o momento de abandonar a doutrina que orientou a teoria do Estado. Disso mesmo se convenceram as várias nações surgidas ou reorganizadas após a conflagração européia. As novas constituïcões da Europa, fôrça é reconhecer, com um de seus mais autorizados analistas, refletem a idéia da supremacia do direito, a idéia da unidade do direito: toda a vida do Estado funda-se no direito e por êle é assegurada. Manifestou-se, em todas elas, o processo da racionalização do poder, a tendência de submeter ao direito todo o conjunto da vida coletiva. Triunfaram, nelas, os princípios democráticos, ou pela instituïção de repúblicas, ou pela democratização de certas monarquias constitucionais. A crise contemporânea, advertiu o mesmo' tratadista, não proveiu do excesso de democratismo e sim da psicologia nacional. E também porque, a despeito dos textos constitucionais inteiramente democráticos, a vida, muitas vezes, escapa às fórmulas juri- 
dicas, sob a influência de velhas tradições despóticas ou nacionalistas (1).

Não pode, sem dúvida, estagnar-se a vida dos povos na imobilidade dos cânones constitucionais. Nem o Estado terá, em todos os tempos, a mesmo função: há de conformar-se com os contingências do meio, coordenando as aspirações de seu povo, atendendo-lhe as necessidades, servindo aos interêsses vitais da coletividade. Demasias de sistemas, insisthências em práticas reprováveis, permanência de preconceitos prejudiciais, tudo isso se corrige e desaparece. A função social do Estado deve desenvolver-se ao máximo, enfrentando e encaminhando para a melhor solução, o problema social em todos os seus aspectos, amainando a dureza da luta das classes, compondo o industrialismo com o proletariado e fixando regras para o seu desenvolvimento paralelo eficiente.

Para a consecução dêsse desiderato, não basta, como se supõe, um governo forte, discricionário e irresponsável, dispensado de caução. O fascismo, por exemplo, liberou-se de responsabilidades para com o povo: assumiu-as para com o rei, em que o simboliza. Os seus poderes, entretanto, do soberano lhe não resultam e sim do partido fascista, em que realmente, está a sua fôrça.

$O$ essencial, para a manutenção de um govêrno e para o seu desenvolvimento eficaz e proveitoso, não é só a fôrça de suas armas, mas principalmente a confiança nacional. Quando êle nesta repousa, não há expansão de direitos individuais que causem embaraços ao da coletividade, limitar-se-ão todas as aspirações particulares em face do interêsse geral.

Jamais, no Brasil, teve o Estado a sua marcha entravada pelos interêsses individuais. Bem ao contrário, encontrou êle os individuos sempre dispostos a todos os sacrificios,

(1) B. MIRKINE-GUETZEVITCH, Les Constituitions de l'Europe Nouvelle, 2." ed., pág. 11. 
suportando, com beneditina paciência, os horrores das administrações desastradas e cumprindo todas as suas exigências, impostas sob o pretexto da utilidade e do bem coletivo nacional.

Se não fôra a confiança do povo no movimento liberal de 1930, e isso mesmo porque como liberal se apresentara, não teria êle saido vitorioso. Venceu. Em agitação ainda está. Não traçou, porém, a sua trajetória. O seu programa de propaganda ficou no ar. Não se disse, depois, ao país, com inteira lealdade, quais os rumos de seus novos destinos. Murmura-se. Promete-se. Ensaia-se. Sucedem-se os decretos tornados letras mortas no mesmo dia de suas publicações. 0 empirismo político e administrativo ainda tateia, indeciso, torturando os espíritos. $\mathrm{E}$ o estado de nebulosidade se prolonga, em todos os sentidos.

Tempo é, pois, meus presados discípulos, e nem convém perdê-lo, de encarar, de frente, a situação brasileira e de reimplantar o regime constitucional. Se, discursando há dias, um dos ministros do ditador asseverou ser a constitucionalizaçãa "mais do que uma aspiração em marcha: é caudal que ninguém deteria", imprudência será sofrear-lhe o impeto torrencial. E crime sem atenuante impor a um povo ordeiro e trabalhador que continue a marcar passos num deserto sem areias, mas também sem homens e sem idéias.

Venha o regime da lei. Nunca teve a nossa gente outra preocupação. Deu por vê-la realizada o máximo de suas energias morais e de suas contribuicções materiais, na mais sugestiva página de civismo de nossa história, cheia de lances épicos e gloriosos. Ponha-se de lado o alvião destruïdor. Está à nossa mão o material suficiente para a obra de reconstrução nacional. Se o império evidenciou as vantagens e os defeitos do presidencialismo, encerrou a república a conta dos prós e dos contra o presidencialismo. Dentro dêsses polos, com os ensinamentos advindos da nossa experiência e da alienígena, encontrar-se-á, certamente, a linha termeira de nossa configuração política. Nada de persona- 
lismo. Para que ressurgir os deuses mortos e envoltos na luminosidade de suas glórias? Nada de implantações de métodos e doutrinas exóticas, incompatíveis com a formação mental de nosso povo e com a realidade geográfica de nosso país. A sua vastidão e a variedade de suas zonas deram ensanchas a civilizações aparentemente idênticas mas efetivamente dissemelhantes. Não se suprem as diferenças de solo e de ar por via de decretos. Nem as econômicas.

Manteve o federalismo o espirito e a unidade nacionais. Estes dois anos de unitarismo, sejamos sinceros, os puseram em grave risco. Justifica-se o erro, mas não se admite a persistência nele. Porque, portanto, alterar o sistema, que tão grandes resultados produziu, sem razão superior? Sòmente porque alguns Estados mais do que outros se desenvolveram? Mas o unitarismo não operará o milagre, que a terra sáfara não permitiu.

Eis, senhores bacharelandos, num rápido golpe de vista, o panorama nacional brasileiro. Surgís para os embates da vida num dos mais delicados momentos. Sereis, por fôrça, chamados a colaborar no plano de reorganização nacional. Seja qual fôr o setor, em que tiverdes de exercitar a vossa atividade, no pretório ou na magistratura, no ministério público ou na polícia, na administração pública ou na diplomacia, no jornalismo ou na tribuna, no comércio ou na indústria, nas letras ou nas artes, praticareis os princípios de liberdade e de honra, que vos foram ministrados neste convento mais que centenário, guarda avançada de todos os grandes movimentos nacionais. Que a vossa conciência jurídica conserve sempre a resistibilidade do aço dos capacetes com que, um dia, cobristes as vossas cabeças juvenis e heróicas. Estai, por isso, sempre alertas e o futuro vos não trará o dissabor dos arrependimentos.

$\mathrm{Eu}$ creio na vossa fôrça e na vossa fé. Bem conheceis as responsabilidades da vossa geração e não faltareis à vossa missão histórica.

Quisestes, à vossa despedida dos bancos acadêmicos, as palavras do vosso professor. São, as que acabais de ouvir, 
palavras do exílio, de gratidão e de saüdade. E também cle confiança na vossa fidelidade ao ideal.

Vencereis : afirmo-o!

O Brasil só não vencerá se não estiver convosco.

Lisboa, dezembro de 1932. 